\title{
Failure analysis for railroad embankment under heavy haul wagon loads
}

\author{
Jin Shi*, Defeng Hou** \\ *Beijing Jiaotong University, Beijing 100044, China, E-mail: jshi@bjtu.edu.cn \\ **Beijing Jiaotong University, Beijing 100044, China \\ cross $^{\text {ref }}$ http://dx.doi.org/10.5755/j01.mech.23.2.13911
}

\section{Introduction}

With growing trends of railroads toward heavier axle loads, higher train speeds, and increasing amount of traffic, higher wheel loads will be exerted on the embankment with more repetition. Excessive embankment foundation deformation, which is often a major problem for railway, will produce high maintenance costs and reduced ride quality. According to the literature [1], foundation failure on the Coal Line were observed during 1994 1995 on the Vryheid-Richard Bay section, approximately 20 years after its initial construction.

Embankment foundation failure caused by large repetitive stresses in the embankment is progressive shear failure and excessive plastic deformation [2]. The design approach for preventing embankment failure is to limit the cumulative plastic strain. Various models have been developed for predicting cumulative plastic strain in soil under repeated loading. In general, the relationship between cumulative plastic strain and number of repeated stress is expressed exponential form [3]-[5]. Li et al [6] improve predicted method considers multilevel of deviator stresses and multisoil physical states that result from load-level variations, as well as seasonal and weather changes. Comparisons between predicted and experimental results show good applicability of the improved method. However, the method uses a value of deviator stress calculated by wheel load without considering vehicle/rail dynamic interaction.

Recent advances in remote condition monitoring techniques have facilitated the field measurement of railway track performance. This, together with the continuing increases in computer power which has enabled theoretical computational models of the track system to be developed, has furthered understanding of embankment failure in a dynamic loading environment.

Yang et al [7] investigated the train induced stress regime of the track substructure by means of a twodimensional dynamic finite-element model (FEM). The model was used to analyse the effects of train speed, acceleration and braking, geometric variation in the rail head level, and hanging sleepers on the calculated stress. However, transient stress of embankment which was analysed is unable properly to consider foundation failure due to repeated train passage.

In recent years, measurements and simulation of embankment culumulative plastic deformation induced by moving trains have been carried out by many railway research departments. Gräbe et al [8] measured permanent deformation of the track foundation, constructed in 2004 ,on the South African Coal Line, gathered over a period of 5 years. Permanent deformation measurements are used to calculate the design life of a foundation. However, little attention has been paid to the effect of rail irregularities, train speed and axle load on foundation failure in operation condition of heavy haul train.

In this paper, a dynamic three-dimensional finite element model using linear elastic material properties while including wheel-rail friction was developed and used to investigate embankment deviator stress. A method is developed for determining failure of embankment. The effect of train speeds, axle load, and rail irregularities on failure of embankment was investigated during repeated train passage. This is described further below.

\section{Embankment foundation failures caused by wagon passage}

Embankment foundation progressive shear failure and excessive plastic deformation (ballast pocket) under truck passage occur mainly in embankment comprised of fine-grained soils and can be related to embankment foundation cumulative plastic strain as represented by following equation [6]:

$$
\varepsilon_{p}(\%)=a\left(\frac{\sigma_{d}}{\sigma_{s}}\right)^{m} N^{b}
$$

where $\varepsilon_{p}$ is cumulative soil plastic strain, $N$ is the number of repeated stress applications, $\sigma_{d}$ is soil deviator stress caused by train dynamic load, $\sigma_{s}$ is soil compressive strength, $a, m, b$ are parameters dependent on soil type.

In three-dimensional stress state, $\sigma_{d}$ can be determined using the following equation:

$$
\sigma_{d}=\frac{\sqrt{\left[\left(\sigma_{x}^{\prime}-\sigma_{y}^{\prime}\right)^{2}+\left(\sigma_{y}^{\prime}-\sigma_{z}^{\prime}\right)^{2}+\left(\sigma_{z}^{\prime}-\sigma_{x}^{\prime}\right)^{2}+6\left(\tau_{x y}^{2}+\tau_{y z}^{2}+\tau_{z x}^{2}\right)\right]^{2}}}{2},
$$

where $\sigma_{x}^{\prime}, \sigma_{y}^{\prime}$ and $\sigma_{z}^{\prime}$ are the normal compressive effective stresses in the $x, y$ and $z$ directions respectively, and $\tau_{x y}, \tau_{y z}$ and $\tau_{z x}$ are the shear stresses in the $x y, y z$ and $z x$ planes respectively.

For this study, the embankment foundation con- 
sists of three distinct layers, the upper layer of stiff sand gravel(called "GL" for short.), and the middle layer consists of engineering filler made up of at least $50 \%$ gravel, sand and silt(called "FL" for short). The bottom layer is of medium strength sand silt (called "SL" for short). The material parameters of gravel and engineering filler were estimated from testing results of cyclic loads measured on Kongshan test section of Beijing-Shanghai railway in China [9].The values so determined in this study are given in Table 1.

In Table $1, \sigma_{s}$ is soil compressive strengths. For stiff, medium, and soft embankment, the range of soil compressive strength is about $200 \sim 350 \mathrm{MPa}$, $100 \sim 200 \mathrm{MPa}$ and $35 \sim 100 \mathrm{MPa}$ respectively suggested by Li [6]. For this study, compressive strength of gravel and engineering filler which are stiff foundation were used value of upper limit and lower limit for stiff embankment respectively. Compressive strength of silt sand which is medium foundation was used lower value for medium embamkment. The soil compressive strengths for various soil types in this paper are shown in Table 1.

Table 1

Values of soil parameters for various soil type

\begin{tabular}{|c|c|c|c|c|}
\hline Soil type & $a$ & $b$ & $m$ & $\sigma_{s}, \mathrm{MPa}$ \\
\hline Gravel & 0.52 & 0.15 & 1.49 & 350 \\
\hline Filler & 0.85 & 0.14 & 1.16 & 200 \\
\hline Silt sand & 0.64 & 0.10 & 1.7 & 100 \\
\hline
\end{tabular}

The number of load repetitions, $N$ to which the embankment material would be subject was determined using Eq. (3):

$$
N=\frac{T_{d} g}{8 L_{s}},
$$

where $T_{d}$ is the total number of gross tones carried over the subgrade over the design life, $L_{s}$ is static load.

The design approach for preventing foundation progressive shear failure is to limit the total cumulative plastic strain at the embankment foundation surface to below an allowable level for the period. This criterion is thus expressed by following equation:

$$
\varepsilon_{p} \leq \varepsilon_{p a}
$$

where $\varepsilon_{p a}$ is allowable plastic strain at the foundation surface for design period. Limiting value of plastic strain of $\varepsilon_{p a}=2 \%$ suggested by Li and Selig [2].

\section{Development of a three-dimensional finite element model}

In order to facilitate the design of appropriate embankment which would minimize vibration of the track components and track deterioration, a three dimensional dynamic finite element model (FEM) of the track vehicle system was built using ABAQUS explicit software.

The track components consisted of $75 \mathrm{~kg} / \mathrm{m}$ continuously welded rail laid to a gauge of $1435 \mathrm{~mm}$, supported by concrete sleepers placed at a spacing of $0.6 \mathrm{~m}$. The ballast thickness is about $0.6 \mathrm{~m}$. The embankment foundation consists of three distinct layers: the upper layer of stiff sand gravel (approximately $0.7 \mathrm{~m}$ deep), and the middle layer of $2.3 \mathrm{~m}$ deep consists of engineering filler made up of at least $50 \%$ gravel, sand and silt and is specified in the Chinese design standard to be of "Class A". The bottom layer of $3.0 \mathrm{~m}$ is of medium strength sand silt.

The embankment was modeled as a threedimensional dynamic system. Solid linear elastic elements, with eight nodes, were used to model the rail, sleepers, ballast and embankment foundation. The embankment foundation was modeled as three layers. Parametric properties are given Table 2. In addition, vertical stiffness and damping of fastener are $78 \mathrm{kN} / \mathrm{mm}$ and $50 \mathrm{kN} \mathrm{s} / \mathrm{m}$. The length of embankment model in longitudinal was $100 \mathrm{~m}$, the depth of model was set at $20 \mathrm{~m}$. Infinite elements were used at the boundaries of the embankment to overcome the problem of the stress waves generated from being reflected back into the model. The finite element mesh, shown in Fig. 1, comprised of a total of 124357 elements and 176268 nodes.

Materials properties parameters in FE model

\begin{tabular}{|c|c|c|c|}
\hline $\begin{array}{c}\text { Component } \\
\text { description }\end{array}$ & $\begin{array}{c}\text { Young's } \\
\text { modulus, } \\
\mathrm{MPa}\end{array}$ & $\begin{array}{c}\text { Poisson's } \\
\text { ratio }\end{array}$ & $\begin{array}{c}\text { Density, } \\
\mathrm{kg} / \mathrm{m}^{3}\end{array}$ \\
\hline Rail & 210000 & 0.3 & 7830 \\
\hline Sleeper & 35000 & 0.22 & 2600 \\
\hline Ballast & 180 & 0.27 & 1650 \\
\hline Sand gravel & 180 & 0.3 & 2300 \\
\hline $\begin{array}{c}\text { Engineering } \\
\text { filler A }\end{array}$ & 130 & 0.3 & 2100 \\
\hline Silt sand & 50 & 0.25 & 1800 \\
\hline
\end{tabular}

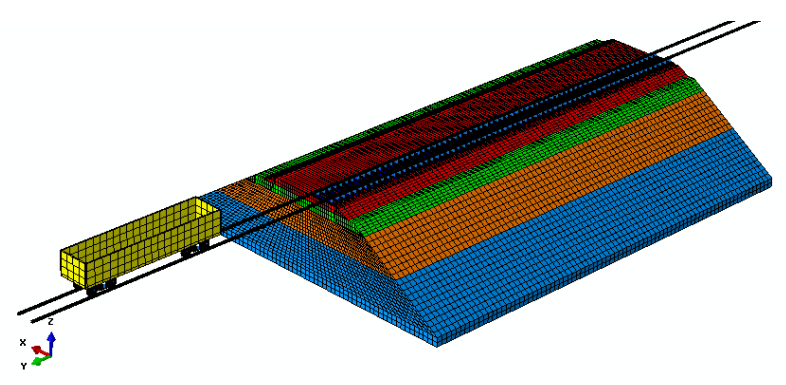

Fig. 1 FE model for dynamic analysis

The wagon consists of a car body, bogie and wheel set, with spring-dashpot suspensions between those components as shown in Fig. 2. The associated parameters of those components are given in Table 3. The connections of suspension system are modelled as a system of linear springs and viscous dashpots in the vertical direction. Wagon vibration in the vertical plane only was considered. With the above assumptions, the car body is designated by vertical, pitching and rolling movements. For the bogie, vertical, pitching and rolling movements are considered. For the wheel set, vertical and rolling movements are considered. So the idealized model for a wagon can be described as 17 degrees of freedom. 


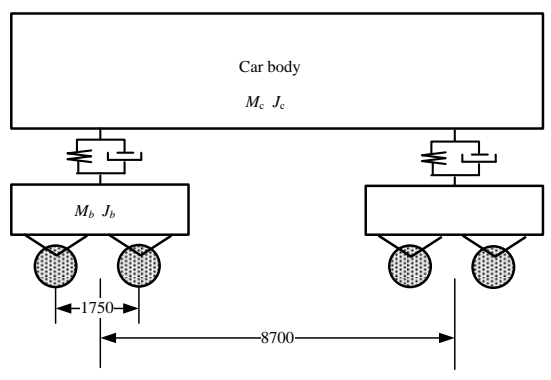

a

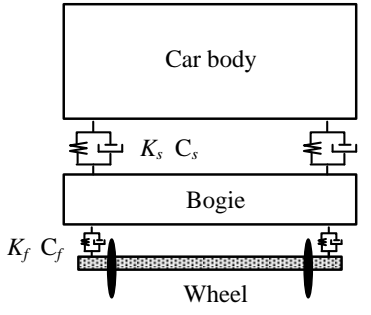

b

Fig. 2 Idealized freight vehicle: $\mathrm{a}$ - the vertical section; $\mathrm{b}$ - the cross section

Table 3

Wagon parameters

\begin{tabular}{|c|c|}
\hline Mass of car body, $M_{c}$ & $91400 \mathrm{~kg}$ \\
\hline Inertia of car body, $J_{c}$ & $1.33 \times 10^{5} \mathrm{~kg} \mathrm{~m}{ }^{2}$ \\
\hline Mass of bogie, $M_{b}$ & $1786 \mathrm{~kg}$ \\
\hline Inertia of bogies, $J_{b}$ & $420 \mathrm{~kg} \mathrm{~m}$ \\
\hline Mass of wheel, $M_{w}$ & $1257 \mathrm{~kg}$ \\
\hline Primary suspension stiffness, $K_{f}$ & $13 \mathrm{MN} / \mathrm{m}$ \\
\hline Primary suspension damping, $C_{f}$ & $3 \times 10^{5} \mathrm{Ns} / \mathrm{m}$ \\
\hline Secondary suspension stiffness, $K_{s}$ & $4.4 \mathrm{MN} / \mathrm{m}$ \\
\hline Secondary suspension damping, $C_{s}$ & $4 \times 10^{3} \mathrm{Ns} / \mathrm{m}$ \\
\hline
\end{tabular}

The contact normal force between the wheel and rail was modelled as Hertzian [10]. The normal contact force $P(t)$ can be determined using the following equation:

$$
P(t)=\left(\frac{1}{G} \Delta Z(t)\right)^{3 / 2},
$$

where $\Delta Z(t)$ is the elastic compression between the rail and wheel (in m), $G$ is the contact constant and is given by:

$$
G=3.86 R^{-0.115} \times 10^{-8}\left(\mathrm{~m} / \mathrm{N}^{3 / 2}\right),
$$

where $R$ is radius of wheel.

The creep force between the wheel-rail is given by:

$$
\tau_{c r i t}=\mu p,
$$

where $\mu$ is the coefficient of friction which was set to 0.3 .

\section{Failure analysis for embankment foundation}

\subsection{Effect of train speed}

In this section, the effect of train speed on foundation stress, cumulative strain and design life were investigated. In the FE model, the wagon with axle load of $250 \mathrm{kN}$ ran along the rail at speeds of 40,60, 80, 100, $120 \mathrm{~km} / \mathrm{h}$. The annual tonnage of $100,200,300$ and $400 \mathrm{Mt}$ were selected to estimate life of embankment.

Fig. 3, a shows the calculated deviator stress at different depth of foundation at different train speeds. Fig. 3, b shows the calculated cumulative plastic strain at different depth of foundation at different train speeds. According to the strain criteria $(2 \%)$, the number of cycles and the life for foundation failure is summarized in Fig. 3, c and Table 4 respectively.

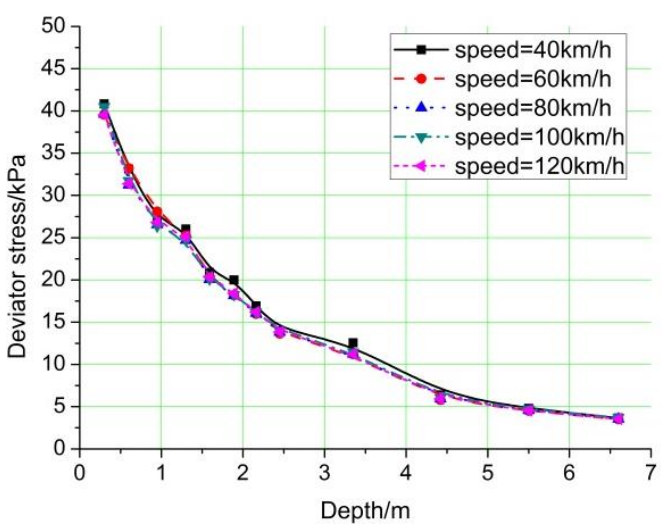

a

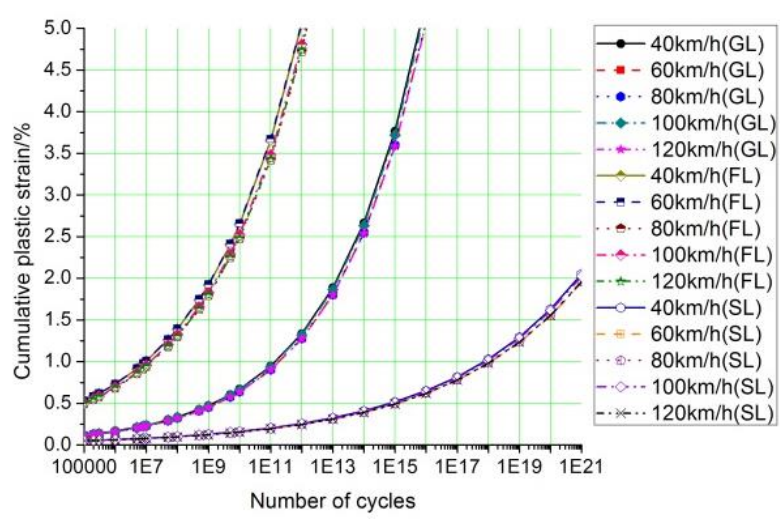

b

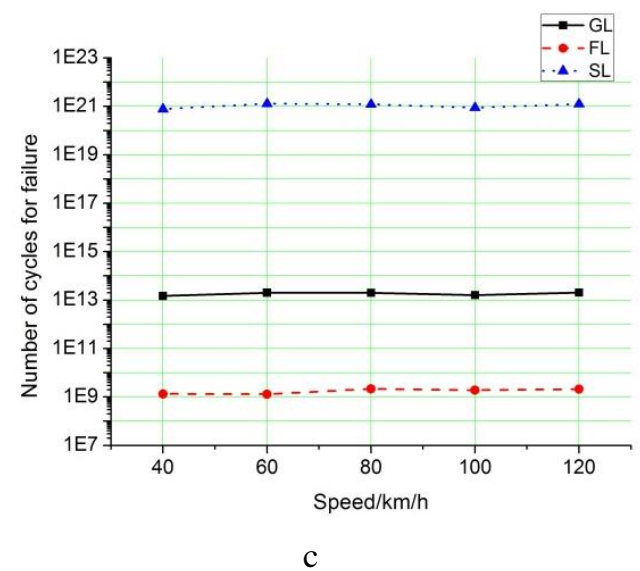

Fig. 3 The effect of train speed on foundation failure: a - deviator stress at different depth of foundation at different train speeds; $b$ - cumulative plastic strain at different depth of foundation at different train speeds; $\mathrm{c}$ - the number of cycles for foundation failure 
The analysis indicates that increasing train speed has little effect on foundation failure in current operation speed range (speed $<120 \mathrm{~km} / \mathrm{h}$ ). It can be seen that failure occurs first in filler layer instead of gravel layer, and there is a rapidly decrease in foundation life which was deter- mined by fill layer failure as annual tonnage is increased. As annual tonnage is increased beyond $400 \mathrm{Mt}$, the foundation life cannot meet a projected design life of 40 years. This means that rehabilitation should be commenced to meet mass transit.

Table 4

Life of foundation at different train speeds

\begin{tabular}{|c|c|c|c|c|c|c|}
\hline $\begin{array}{c}\text { Speed, } \\
\mathrm{km} / \mathrm{h}\end{array}$ & $\begin{array}{c}\text { Number of cycles for } \\
\text { foundation failure }\end{array}$ & $\begin{array}{c}\text { The total number of gross tones } \\
\text { for foundation failure, Mt }\end{array}$ & \multicolumn{3}{|c|}{ Design life of foundation, year } \\
\cline { 4 - 7 } & $1.33 \times 10^{9}$ & 13300 & 133 & 66.5 & 44.3 & 33.3 \\
\hline 40 & $1.31 \times 10^{9}$ & 13100 & 131 & 65.5 & 43.7 & 32.8 \\
\hline 60 & $2.17 \times 10^{9}$ & 21700 & 217 & 108.5 & 72.3 & 54.3 \\
\hline 80 & $1.90 \times 10^{9}$ & 19000 & 190 & 95 & 63.3 & 47.5 \\
\hline 100 & $2.10 \times 10^{9}$ & 21000 & 210 & 105 & 70 & 52.5 \\
\hline 120 & & & & & & \\
\hline
\end{tabular}

\subsection{Effect of axle load}

In this section, the effect of axle load on foundation stress, cumulative strain and design life were investigated. At heavy haul railway, a typical wagon may apply the axle load of $210 \mathrm{kN}$ and $250 \mathrm{kN}$, the wagon with axle load of $300 \mathrm{kN}$ will be applied to increase volume in the future. The speed of the wagon running through the subgrade was $100 \mathrm{~km} / \mathrm{h}$.

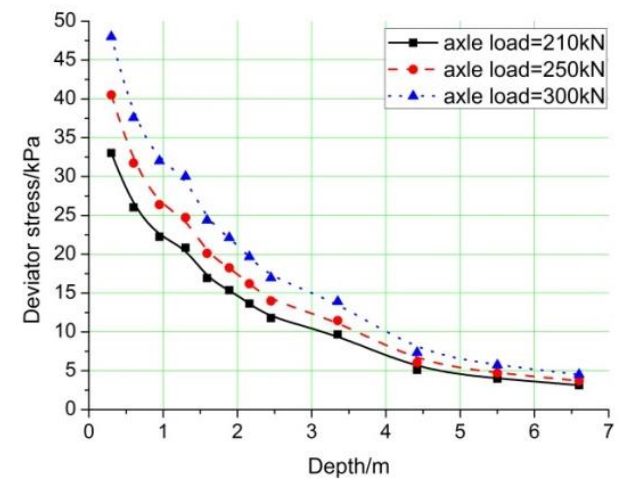

a

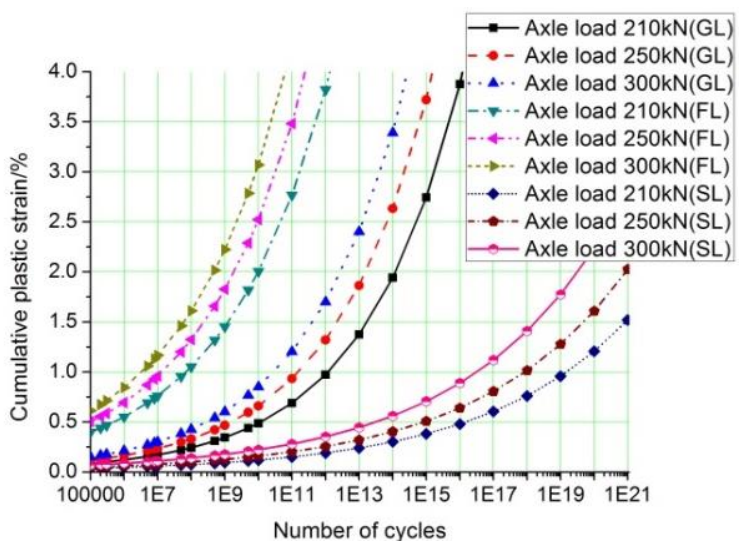

b

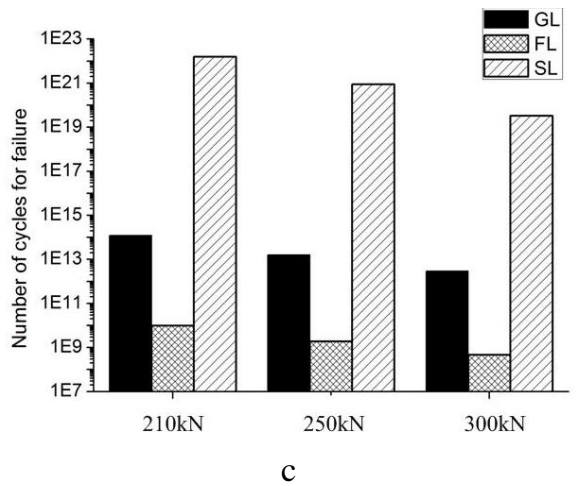

Fig. 4 The effect of axle load on foundation failure: a - deviator stress for three types of axle load at different depth of foundation; $b$ - cumulative plastic strain for three types of axle load at different depth of foundation; $c$ - the number of cycles for foundation failure

Fig. 4, a shows the calculated deviator stress for three types of axle load at different depth of foundation. The effect of the change in axle load on the deviator stresses is such that the calculated deviator stress increase in the foundation caused by a wagon with an axle load of $300 \mathrm{kN}$ is greater than for an axle load of $250 \mathrm{kN}$ for a wagon moving, and the deviator stress caused by a wagon with axle load of $250 \mathrm{kN}$ is greater than for an axle load of $210 \mathrm{kN}$. This is particularly evident at depth of $0 \sim 4 \mathrm{~m}$ in foundation.

Fig. 4, b shows the calculated cumulative plastic strain for three types of axle load at different depth of foundation. As with the cumulative plastic strain of foundation, there is a gradual increase in plastic strain as the 
axle load increase from 210 to $300 \mathrm{kN}$. According to the strain criteria, the number of cycles and the life for foundation failure is summarized in Fig. 4, c and Table 5 respectively. It can be seen that failure occurs first in filler layer instead of gravel layer, and there is a rapidly decrease in foundation life which was determined by fill layer failure as axle load is increased. The life of foundation for axle load of $250 \mathrm{kN}$ is about $80 \%$ less than for axle load of
$210 \mathrm{kN}$, and the life for axle load of $300 \mathrm{kN}$ is about $75 \%$ less than for axle load of $250 \mathrm{kN}$. The analysis also showed that the foundation life with axle load of $300 \mathrm{kN}$ is less than 60 years for annual tonnage $100 \mathrm{Mt}, 30$ years for annual tonnage $200 \mathrm{Mt}, 20$ years for annual tonnage $300 \mathrm{Mt}$, 15 years for annual tonnage $400 \mathrm{Mt}$. This suggests that the foundation should be upgraded to handle wagon trains with axle load of $300 \mathrm{kN}$.

Table 5

Life of foundation with different types of axle load

\begin{tabular}{|c|c|c|c|c|c|c|}
\hline \multirow{2}{*}{$\begin{array}{c}\text { Axle } \\
\text { load, } \mathrm{kN}\end{array}$} & $\begin{array}{c}\text { Number of cycles for } \\
\text { foundation failure }\end{array}$ & $\begin{array}{c}\text { The total number of gross tones for } \\
\text { foundation failure, Mt }\end{array}$ & \multicolumn{4}{|c|}{ Design life of foundation, year } \\
\cline { 3 - 7 } & $9.80 \times 10^{9}$ & 82400 & 824 & 412 & 275 & 206 \\
\hline 210 & $1.90 \times 10^{9}$ & 19000 & 190 & 95 & 63.3 & 47.5 \\
\hline 250 & $4.69 \times 10^{8}$ & 5630 & 56.3 & 28.2 & 18.8 & 14.1 \\
\hline 300 & & & & & & \\
\hline
\end{tabular}

\subsection{Effect of rail irregularities}

Rail irregularities are a major source of vibration for moving trains. In railway engineering practice, the track irregularity is frequently characterized by the onesided power spectral density (PSD) function of the track geometry. The PSD functions used in the study are given as follows [11]:

$$
S_{v}(\Omega)=\frac{k A_{v} \Omega_{c}^{2}}{\Omega^{2}\left(\Omega^{2}+\Omega_{c}^{2}\right)},
$$

where $S_{v}(\Omega)$ is a power spectral density(PSD) function , $\mathrm{cm}^{2} /(\mathrm{rad} / \mathrm{m}) ; A_{v}$ is the irregularities coefficient, $\mathrm{cm}^{2} \mathrm{rad} / \mathrm{m}$; $\Omega=1 / \lambda$ denotes the spatial frequency, $\mathrm{Hz} ; \lambda$ is the length of the irregularity, $\mathrm{m} ; \Omega_{c}$ is frequencies than change the shape of $S_{v}(\Omega), k$ is safety coefficient $(0.25)$.

Table 6 contains the values for the coefficients involved in Eq. (8), which are equivalent to classes 5 and 6 of track classification used by the Federal Railroad Administration (FRA). The track classes refer to track designations that range from 1 to 6 , with class 6 indicating the best and class 1 the worst. In the study, class 6 and 5 were selected to simulate good and poor quality rail.

Table 6

The values for the coefficients of PSD functions

\begin{tabular}{|c|c|c|c|}
\hline Quality & $\begin{array}{c}\Omega_{c}, \\
\mathrm{rad} / \mathrm{m}\end{array}$ & $\begin{array}{c}A_{v}, \\
\mathrm{~cm}^{2} \mathrm{rad} / \mathrm{m}\end{array}$ & $\begin{array}{c}\text { Maximum } \\
\text { speed, } \mathrm{km} / \mathrm{h}\end{array}$ \\
\hline Poor(FRA5) & 0.8245 & 0.2095 & 128 \\
\hline Good(FRA6) & 0.8245 & 0.0339 & 176 \\
\hline
\end{tabular}

By applying the spectral representation method, rail irregularities time domain samples for FRA5 and FRA6 were shown in Fig. 5. Fig. 5 shows the maximum amplitude of moderate and poor quality rail are $5 \mathrm{~mm}$ and $10 \mathrm{~mm}$ respectively.

In this section, the effect of irregularities on foundation stress, cumulative strain and design life were investigated. In FE model, the wagon with axle load $250 \mathrm{kN}$ ran

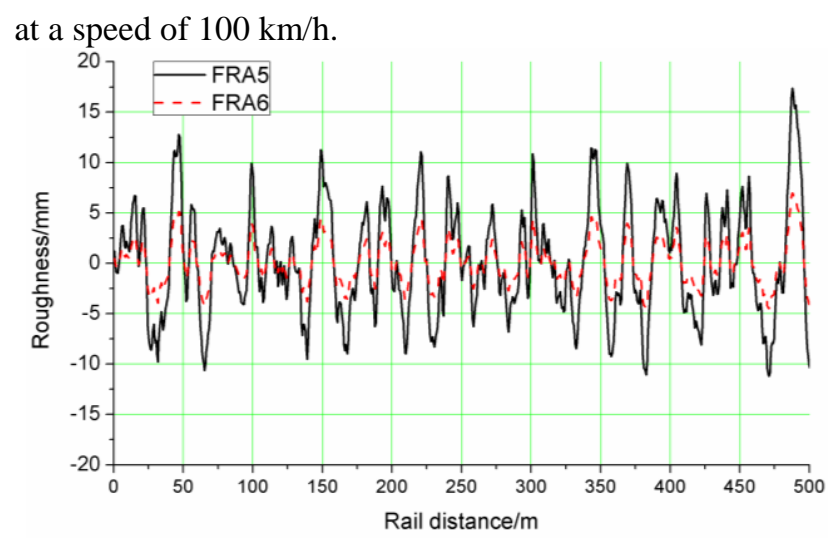

Fig. 5 Rail irregularities in time domain

Fig. 6, a shows the calculated deviator stress for three types of rail irregularities at different depth of foundation. Values of deviator stress with FRA6 or without irregularities are very different, but the values with FRA5 are greater than those of the other two cases. From these it is evident that train-induced vibrations under poor irregularities have important influence on the stress of foundation and suggests that the irregularities for amplitude of more than $5 \mathrm{~mm}$ will accelerate deterioration in the foundation.

Fig. 6, b shows the calculated cumulative plastic strain for three types of rail irregularities at different depth of foundation. It may be seen that the cumulative plastic strain with FRA5 irregularities are always higher than that with FRA6 or without irregularities. According to the strain criteria, the number of cycles and the life for foundation failure is summarized in Fig. 6, c and Table 7 respectively. It can be seen that failure occurs first in filler layer instead of gravel layer. Poor quality irregularities reduce the life of the foundation by approximately $75 \sim 80 \%$. The analysis also showed that the foundation life with FRA5 irregularities are less than 40 years for annual tonnage $100 \mathrm{Mt}, 20$ years for annual tonnage $200 \mathrm{Mt}, 15$ years for annual tonnage $300 \mathrm{Mt}, 10$ years for annual tonnage $400 \mathrm{Mt}$. This suggests that the rail maintainment should be strengthen to prevent foundation shear failure in short time. 


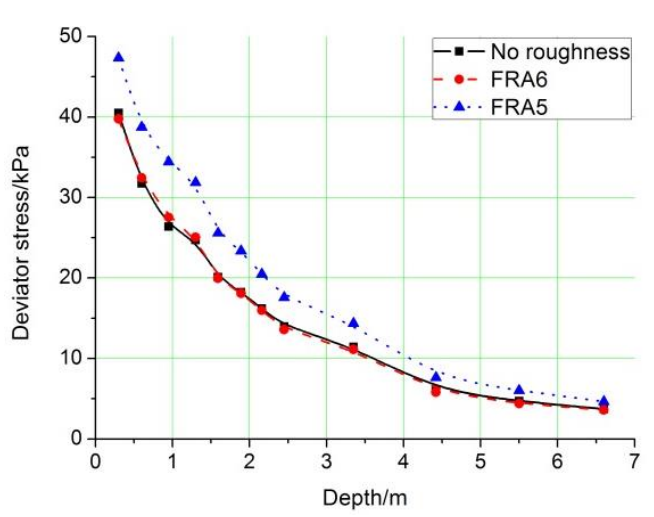

a

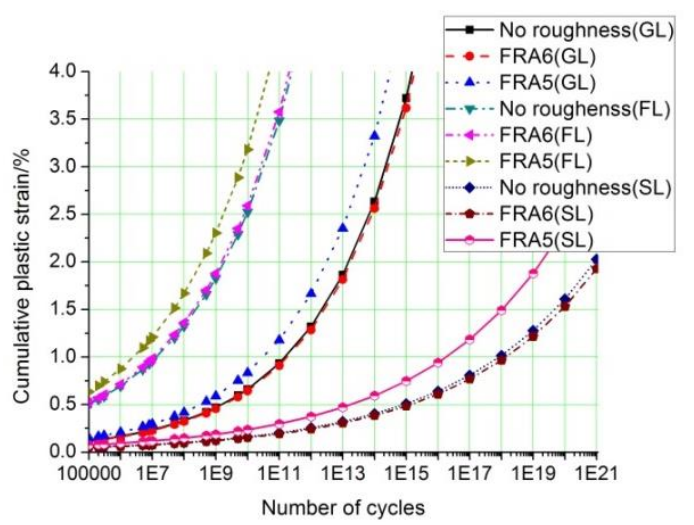

b

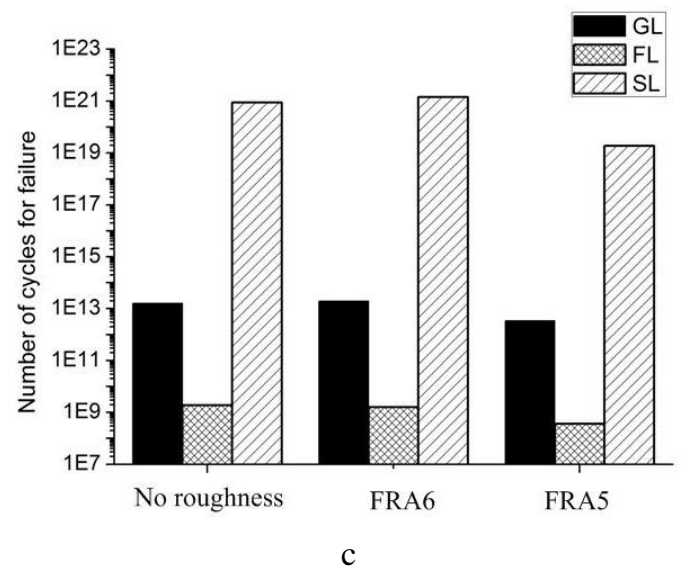

Fig. 6 The effect of irregularities on foundation failure: a - deviator stress for three types of rail irregularities at different depth of foundation; $b$ - cumulative plastic strain for three types of rail irregularities at different depth of foundation; $\mathrm{c}$ - the number of cycles for foundation failure

Life of foundation with different types of irregularities

\begin{tabular}{|c|c|c|c|c|c|c|}
\hline \multirow[t]{2}{*}{ Track condition } & \multirow{2}{*}{$\begin{array}{l}\text { Number of cycles for } \\
\text { foundation failure }\end{array}$} & \multirow{2}{*}{$\begin{array}{c}\text { The total number of gross } \\
\text { tones for foundation failure, } \\
\mathrm{Mt}\end{array}$} & \multicolumn{4}{|c|}{ Design life of foundation (year) } \\
\hline & & & $100 \mathrm{Mt}$ & $200 \mathrm{Mt}$ & $300 \mathrm{Mt}$ & $400 \mathrm{Mt}$ \\
\hline Without irregularities & $1.90 \times 10^{9}$ & 19000 & 190 & 95 & 63.3 & 47.5 \\
\hline FRA6 & $1.58 \times 10^{9}$ & 15800 & 158 & 79 & 52.7 & 39.5 \\
\hline FRA5 & $3.64 \times 10^{8}$ & 3640 & 36.4 & 18.2 & 12.1 & 9.1 \\
\hline
\end{tabular}

\section{Conclusions}

A dynamic three-dimensional finite element model using linear elastic material properties while including wheel-rail friction was developed and used to investigate embankment deviator stress.

A method is developed for determining failure of embankment. The effect of train speeds, axle load, and rail irregularities on failure of embankment was investigated during repeated train passage.

Train speed has little effect on foundation failure in current operation speed range (speed $<120 \mathrm{~km} / \mathrm{h}$ ), however, axle load and irregularities have important effect on foundation failure. This suggests that the foundation should be upgraded to handle wagon trains with axle load of $300 \mathrm{kN}$, and rail maintainment should be strengthen to prevent foundation shear failure in short time .

Embankment failure occurs first in filler layer instead of gravel layer, and there is a rapidly decrease in foundation life which was determined by fill layer failure as annual tonnage is increased. As annual tonnage is increased beyond $400 \mathrm{Mt}$, the foundation life cannot meet a projected design life of 40 years. This means that rehabilitation should be commenced to meet mass transit.

\section{Acknowledgements}

This work was supported by the Fundamental Research Funds for the Central Universities (2014JBZ012).

\section{References}

1. Gräbe, P.J.; Shaw, F.J. 2009. Design life prediction of a heavy haul track foundation, Proc. IMechE, Part F: J. Rail and Rapid Transit 224(1): 337-344.

2. Li, D.;Selig, E.T. 1998. Method for railroad track foundation design. I: Development, Journal of Geotechnical and Geoenvironmental Engineering, ASCE 124(4):316-322.

http://dx.doi.org/10.1061/(ASCE)1090- 
0241(1998)124:4(316)

3. Monismith, C.L.; Ogawa, N.; Freeme, C.R. 1975. Permanent deformation characteristics of subgrade soils due to repeated loading, Transportation Research Board 537: 1-17.

4. Burrow, M.P.N.; Chan, A.H.C. 2007. Deflectometerbased analysis of ballasted railway tracks, Geotechnical Engineering 160(GE3): 169-177. http://dx.doi.org/10.1680/geng.2007.160.3.169.

5. Ju, S.H.; Liao, J.A; Ye, Y.L. 2009. Behavior of ground vibration induced by trains moving on embankments with rail roughness, Soil Dynamics and Earthquake Engineering 20: 1237-1249.

6. Li, D.; Selig, E.T. 1994. Resilient modulus for finegrained subgrade soils, Journal of Geotechnical Engineering, ASCE 120(6): 939-957. http://dx.doi.org/10.1061/(ASCE)07339410(1994)120:6(939).

7. Yang, L.A.; Powrie, W.; Priest, J.A. 2009. Dynamic stress analysis of a ballasted railway track bed during train passage, Journal of Geotechnical and Geoenvironmental Engineering 135(5): 680-689. http://dx.doi.org/10.1061/(ASCE)GT.19435606.0000032 .

8. Gräbe, P.J.; Clayton, C.R.I. 2009. Effects of principal stress rotation on permanent deformation in rail track foundations, Journal of Geotechnical and Geoenvironmental Engineering 135(4): 555-565. http://dx.doi.org/10.1061/(ASCE)10900241(2009)135:4(555).

9. Dong, L.; Cai, D.G.; Zhao, C.G. 2010. Method for predicting the cumulative deformation of high-speed railway subgrade under cyclic train loads, China Civil Engineering Journal 43(6): 100-108. (in Chinese)

10. Zhai, W.M.; Wang, K.Y.; Lin, J.H. 2007. Modeling and experiment of railway ballast vibrations, Journal
Sound and Vibration 270(4): 673-683.

11. Fries, R.H.; Coffey, B.M. 1990. A state-space approach to the synthesis of random vertical and crosslevel rail irregularities, Journal Dynamic System, Measurement and Control 112(1): 83-87. http://dx.doi.org/10.1115/1.2894143.

Jin Shi, Defeng Hou

\section{FAILURE ANALSIS FOR RAILROAD EMBANKMENT UNDER HEAVY HAUL WAGON LOADS}

S u m m a r y

In this paper, a dynamic three-dimensional finite element model using linear elastic material properties while including wheel-rail friction was developed and used to investigate embankment deviator stress. The effect of train speeds, axle load, and rail roughness on failure of embankment was investigated during repeated train passage. Results indicate that axle load and rail roughness have important effect on foundation failure. Embankment failure occurs first in engineering filler layer instead of gravel layer, and there is a rapidly decrease in foundation life which was determined by fill layer failure as annual tonnage is increased. As annual tonnage is increased beyond $400 \mathrm{Mt}$, the foundation life cannot meet a projected design life of 40 years.

Keywords: embankment, finite element, dynamic response, failure, repeated load.

Received January 03, 2016

Accepted April 14, 2017 